\title{
Clinic blood pressure measurements and blood pressure load in the diagnosis of hypertension
}

\author{
D.R. Lee, P. Sivakumaran and R. Brown \\ Basildon Hospital, Nethermayne, Basildon, Essex, UK
}

Summary: We have retrospectively compared the blood pressure load derived from 24 hour ambulatory blood pressure monitoring in patients with all clinic blood pressure readings elevated with those with only some elevated pressures to establish whether clinic readings alone are good predictors of blood pressure status. Fifty-seven patients attending a district general hospital hypertension clinic who were not on anti-hypertensive treatment were selected.

Between two and six clinic readings were taken over a period of 1-6 months. Forty out of 57 patients had at least one clinic diastolic blood pressure reading of $<90 \mathrm{mmHg}$ and, of these, $14(35 \%)$ had a high blood pressure load and $26(65 \%)$ had a normal blood pressure load. Patients with all diastolic blood pressure readings $>90 \mathrm{mmHg}$ totalled 17 and of these $11(65 \%)$ had high load and six (35\%) had normal load. Patients with clinic diastolic blood pressure $>90 \mathrm{mmHg}$ were significantly more likely to be truly hypertensive on the basis of blood pressure load than if one or more clinic readings was below $90 \mathrm{~mm} H \mathrm{~g}$ $(P<0.05)$. Diastolic pressures have some predictive power as to the blood pressure status defined by blood pressure load, but even consistently raised diastolic pressures do not necessarily indicate hypertension. Likewise one or more clinic diastolic blood pressure $<90 \mathrm{mmHg}$ does not assuredly indicate normotension. Twenty-four hour ambulatory blood pressure monitoring may have an increasingly important role in the assessment of hypertension.

\section{Introduction}

There are difficulties in interpreting clinic blood pressure readings as a result of inherent blood pressure variability ${ }^{1,2}$ including the 'white coat' effect. ${ }^{3}$ A patient's clinic blood pressure readings may vary from normotensive to hypertensive causing diagnostic and therapeutic indecision even after frequent clinic attendance. Blood pressure 'load' (BP load), a new concept, is measurable using ambulatory blood pressure monitoring (ABPM) and has been shown to correlate well with the markers of cardiovascular morbidity. ${ }^{4-6}$

In this paper we compare the BP load in patients with all clinic blood pressure readings elevated with those with only some elevated pressures to establish whether clinic readings alone are good predictors of blood pressure status.

\section{Methods}

Twenty-four hour ABPM using the Oxford Medilog system ${ }^{7}$ was performed on 57 patients whose clinic BP was $>140 / 190 \mathrm{mmHg}$ on at least

Correspondence: D.R. Lee, M.R.C.P., Clinical Age Research Unit, King's College Hospital, Denmark Hill, London SE5 9RS, UK

Accepted: 14 December 1992 one occasion. As defined by White, ${ }^{4} \mathrm{BP}$ load is the percentage of blood pressure $>140 / 190 \mathrm{mmHg}$ by $\cong$ day and $120 / 80 \mathrm{mmHg}$ at night (11 p.m. to 7 a.m.) $\stackrel{\square}{\complement}$ and hypertension is said to be present when $40 \% \overrightarrow{\vec{P}}$ systolic and/or diastolic readings exceed these levels.

These patients were divided into four groups: (1) at least one clinic systolic BP reading $\angle 140 \div$ $\mathrm{mmHg}$; (2) all clinic systolic BP readings $>140 \mathrm{mmHg}$; (3) at least one clinic diastolic BP $\dot{\sigma}$ reading $<90 \mathrm{mmHg}$; (4) all clinic diastolic $\mathrm{BP} \stackrel{3}{.}$. readings $>90 \mathrm{mmHg}$. Each group was further $ᄋ$ subdivided into those patients with a normal pressure load and those with a high pressure load. 웅

The BP loads of those in Group 1 were statis- $D$ tically compared with those in Group 2 , and similarly the BP loads of those in Group 3 with Group 4 using the chi square test without Yates of correction or Fisher's exact test as the expected N values were $>5$.

\section{Results}

Twenty-three women and 34 men aged $18-72$ were $T$ studied. The mean age was 40.8 years (s.d. 13.4). Between two and six clinic blood pressure readings had been recorded prior to ABPM over a period of 
Table I Group characteristics and BP load distribution of 57 hypertensive patients grouped by nature of clinic readings

\begin{tabular}{|c|c|c|c|c|c|c|}
\hline \multicolumn{2}{|c|}{ Group } & \multirow{2}{*}{$\begin{array}{l}n \\
23\end{array}$} & \multirow{2}{*}{$\begin{array}{c}\begin{array}{c}\text { Age range } \\
\text { (mean) }\end{array} \\
20-55 \\
(36.3)\end{array}$} & \multirow{2}{*}{$\begin{array}{c}\begin{array}{c}\text { Range of number } \\
\text { of clinic readings } \\
\text { recorded (median) }\end{array} \\
2-6 \\
(4)\end{array}$} & \multirow{2}{*}{$\begin{array}{c}\begin{array}{c}\text { Normal load } \\
(\%)\end{array} \\
16 \\
(70 \%)\end{array}$} & \multirow{2}{*}{$\begin{array}{c}\begin{array}{c}\text { High load } \\
(\%)\end{array} \\
7 \\
(30 \%)\end{array}$} \\
\hline 1 & $\begin{array}{l}\text { At least one clinic } \\
\text { systolic reading } \\
<140 \mathrm{mmHg}\end{array}$ & & & & & \\
\hline 2 & $\begin{array}{l}\text { All clinic systolic } \\
\text { readings } \\
>140 \mathrm{mmHg}\end{array}$ & 34 & $\begin{array}{l}20-72 \\
(43.7)\end{array}$ & $\begin{array}{l}2-6 \\
(3)\end{array}$ & $\begin{array}{c}17 \\
(50 \%)\end{array}$ & $\begin{array}{c}17 \\
(50 \%)\end{array}$ \\
\hline 3 & $\begin{array}{l}\text { At least one clinic } \\
\text { diastolic reading } \\
<90 \mathrm{mmHg}\end{array}$ & 40 & $\begin{array}{l}20-65 \\
(38.9)\end{array}$ & $\begin{array}{c}2-6 \\
(3)\end{array}$ & $\begin{array}{c}26 \\
(65 \%)\end{array}$ & $\begin{array}{c}14 \\
(35 \%)\end{array}$ \\
\hline 4 & $\begin{array}{l}\text { All clinic } \\
\text { diastolic readings } \\
>90 \mathrm{mmHg}\end{array}$ & 17 & $\begin{array}{c}20-72 \\
(45.1)\end{array}$ & $\begin{array}{c}2-6 \\
(2)\end{array}$ & $\begin{array}{c}6 \\
(35 \%)\end{array}$ & $\begin{array}{c}11 \\
(65 \%)\end{array}$ \\
\hline
\end{tabular}

1-6 months. The features of each of the four groups and their relationship to BP load are shown in Table I. There was no significant difference between Groups 1 and 2 in terms of BP load $\left(\chi^{2}=3.52, \mathrm{NS}\right)$. The sensitivity of the clinic systolic pressure readings was 0.71 with a specificity of 0.48 . However, concerning diastolic pressures, patients with all clinic readings $>90 \mathrm{mmHg}$ (Group 4) were significantly more likely to have a high load than if at least one clinic reading was $<90 \mathrm{mmHg}$ (Group 3) $\left(\chi^{2}=5.07, P<0.05\right)$. The sensitivity of the clinic diastolic readings was 0.44 with a specificity of 0.81 .

\section{Discussion}

A concept of BP load was first introduced by Zachariah et al. in $1988 .{ }^{8}$ White et al. ${ }^{4}$ took this concept further by taking diurnal variations of blood pressure into account in calculating systolic and diastolic loads. On the basis of markers of cardiovascular morbidity such as left ventricular mass index and left atrial index a threshold for hypertension of $40 \%$ of high readings was produced. We have used this figure as our threshold of hypertension. The age range of our subjects was 18-72 (mean 40.8 years, s.d. 13.4) was comparable with those in White's study (23-72, mean 47, s.d. 12). ${ }^{4}$ However, we recognize that our definition of 'hypertension' does not take age into account and thus is of limited value. Measurements of cardiac target organ damage have been used as a predictor of future morbidity and mortality but longitudinal studies looking directly at BP load and morbidity and mortality have not been performed, and therefore whether ABPM can improve our prediction of morbid events or accurately select patients for treatment has not been firmly established. One recent paper, which took the World Health Organisation-International Society of Hypertension guidelines as the standard for deciding to treat mild hypertensives, concluded that the predictive value of one 12 hour ABPM recording was too low to detect those patients who need treatment according to this standard. ${ }^{9}$

'White coat' hypertension is well documented ${ }^{3,10}$ and is suspected where clinic readings vary from hypertensive to normotensive values. Our results indicate that although patients who have at least one clinic diastolic BP of $<90 \mathrm{mmHg}$ would probably have a normal blood pressure load, a significant number $(35 \%)$ will have a high load. Also where all the diastolic pressures were $>90 \mathrm{mmHg}$ as many as $35 \%$ may have a nonhypertensive pressure load.

Similarly, $50 \%$ of patients with a consistent systolic BP of $>140 \mathrm{mmHg}$ would have a normal load and $30 \%$ of patients with at least one clinic systolic BP of $<140 \mathrm{mmHg}$ would have a high load. This difference did not reach statistical significance but this could be explained by a type 2 error. These findings indicate that clinic readings can be misleading and add to the growing weight of evidence $^{11-14}$ that ABPM has much to offer in the assessment of hypertension.

\section{Acknowledgements}

We thank all those associated with this study and particularly Bayer UK for funding this project. 


\section{References}

1. James, G.D. \& Pickering, T.G. Ambulatory blood pressure monitoring: assessing the diurnal variation of blood pressure. Am J Phys Anthropol 1991, 84: 343-349.

2. Parati, G., Omboni, S., Di-Rienzo, M., Frattola, A., Albini, F. \& Mancia, G. Twenty four hour blood pressure variability: clinical implications. Kidney Int Suppl (June) 1992, 37: S24-28.

3. Pickering, T.G. Clinical applications of ambulatory blood pressure monitoring: the white coat effect. Clin Invest Med 1991, 14: 212-217.

4. White, W.B., Dey, H.M. \& Schulman, P. Assessment of the daily blood pressure load as a determinant of cardiac function in patients with mild to moderate hypertension. $\mathrm{Am}$ Heart $J$ 1989, 118: 782-795.

5. Bauwens, F., Duprez, D., De-Buyere, M. \& Clement, D.L. Blood pressure load determines left ventricular mass in essential hypertension. Int J Cardiol 1992, 34: 335-338.

6. Prisant, L.M., Bottini, P.B. \& Carr, A.A. Clinical utility of ambulatory blood pressure monitoring in target organ complications and equipment choices. J Clin Pharmacol 1992, 32: 620-626.

7. O'Brien, E. \& O'Malley, K. Twenty four hour ambulatory blood pressure monitoring: a review of validation data. $J$ Hypertens 1990, 8 (Suppl 6): S11-S16.

8. Zachariah, P.K., Sheps, S.G., Ilstup, D.M. et al. Blood pressure load - a better determinant of hypertension. Mayo Clin Proc 1988, 63: 1085-1091.
9. Chatellier, G., Battaglia, C., Pagny, J.Y., Plouin, P.F. \& Menard, J. Decision to treat mild hypertension after assessment by ambulatory monitoring and World Health Organisation recommendations. $\mathrm{Br}$ Med J 1992, 305: 1062-1066.

10. Pickering, T.G., James, G.D., Boddie, C., Harshfield, G.A Blank, S. \& Laragh, J.H. How common is white coat hypertension? JAMA 1988, 259: 225-228.

11. The National High Blood Pressure Educating Program Co-ordinating Committee. National High Blood Pressure Education Working Group Report on ambulatory blood pressure monitoring. Arch Intern Med 1990, 150: 2270-2280.

12. Clement, D.L. Office versus ambulatory recordings of blood pressure (OvA): a European multicentre study. The Steering Committee. J Hypertens 1990, 8 (Suppl 6): S39-S41.

13. O'Brien, E.T., Cox, J. \& O'Malley, K. The role of twenty four ambulatory blood pressure measurement in clinical practice. J Hypertens 1991, 9 (Suppl 8): S63-S65.

14. Carr, A.A., Bottini, P.B. \& Prisant, L.M. Ambulatory blood pressure monitoring for evaluation and management of hypertensives: effect on outcome and cost effectiveness. J Clin Pharmacol 1992, 32: 610-613. 